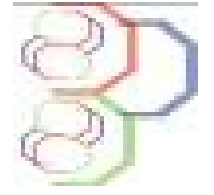

Journal of Applied Biosciences 67:5308 - 5325

\title{
Trends and emerging drugs in Kenya: A case study in Mombasa and Nairobi County
}

\author{
Kahuthia-Gathu R. ${ }^{1,}$, Okwarah P. ${ }^{2}$, Gakunju R. ${ }^{2}$, and Thungu J. ${ }^{3}$ \\ ${ }^{1}$ Kenyatta University, School of Agriculture \& Enterprise Development, PO Box 43844-00100 Nairobi \\ ${ }^{2}$ Movement Against Substance Abuse in Africa (MASAA), National Authority for Campaign Against Alcohol and Drug \\ Abuse (NACADA) P.O. Box 10241-00100, Nairobi \\ 3 Thogoto Teachers College, Private bag, Kikuyu \\ *Corresponding author: rkahuthia@gmail.com
}

Original submitted in on $25^{\text {th }}$ June 2013 Published online at www.m.elewa.org on $30^{\text {th }}$ July 2013.

https://dx.doi.org/10.4314/iab.v67i0.95055

\begin{abstract}
Background: Increasing popularity of emerging drugs or the 'legal high' is of major concern to the Government. Emerging psychoactive substances e.g. morphine, carnabinoids, cathinones are not controlled and are believed to cause harm if not more than controlled drugs. They are being sold all over as legal substances and consumed openly.

Objective: To evaluate the trends and patterns of emerging drugs use, magnitude and their impact in the Counties. Methods: A questionnaire was administered to 702 respondents in Nairobi and Mombasa Counties. The social dynamics, types of emerging drugs, drug initiation age, source of drugs, venue of consumption, and their effects on respondents among other issues were investigated. Qualitative, univariate and multivariate logistic regression analyses were done.

Results: The drug initiation age ranged from 5 to 28 years though most started abusing the drugs at 21 years (18\%), with over $81 \%$ being introduced by friends. They are abused for their stimulating, hallucinating, depressants effects on the streets, club, drug dens, party but rarely at home and schools. Forty one (41) emerging drugs (see text) comprising of one or combinations of drugs were recorded, with Nairobi recording significant higher number of emerging drugs than Mombasa. Most of the highly abused drugs were 'kuber, shisha, shashaman, mau, tambuu, jet fuel, kukumanga, mkorogo, mshomoro, rohypnol, Artaine and kamusi. 'Shisha' and 'kuber' were most commonly abused drugs in both counties. Over $25 \%$ of the shisha and kuber abusers aged between 26 to 35 years. The emerging drugs were purchased drugs from various outlets, thus making it difficult to track. Some respondents injected either heroin or cocaine while others injected both heroin and cocaine thus, placing the individuals at risk of contracting Human Immunodeficiency Virus (HIV) and Hepatitis C. The emerging drugs have a lot of impact on the county's security, economy, education, school drop-out rate, non performance at work place and reproductive health. Conclusion and recommendations: The Government should set up of rehabilitation centres, training programmes on alcohol and drug abuse, establish Employee Assistant Programmes, wellness centres, control sale of prescription medicine, stiff penalties on drug peddlers and ban of advertisement on media. There is need for all stakeholders to review the alcohol and Drug Abuse policy to include new and emerging drugs in order to mitigate illnesses deaths and associated with emerging drugs. Government should come up with ways of tracking and controlling the emerging drugs especially shisha, kuber, and prescription medicine. Alcohol and Drug Abuse (ADA) issues should be incorporated in the education curriculum at all levels.
\end{abstract}


Key words: Emerging drugs, shisha, kuber, causes, mitigations, combinations, administration

\section{INTRODUCTION}

The term "drugs of abuse" usually brings to mind traditional street drugs, such as cocaine, heroin, marijuana, and methamphetamine (Stephen et al., 2011). The drug scene, however, is constantly evolving (Albert and Ostheimer, 2002). As various law enforcement agencies (Anti-Narcotics, Pharmacy and Poisons Board) pursue and dismantle distribution and production, organizations of the usual drugs of abuse, dealers and users are turning to less known, more accessible, and often currently legal substances. The widespread growth of the Internet with its vast distribution of information has increased the accessibility of a host of substances and facilitated synthesis and production of various substances by individuals (Evans-Brown et al., 2011). The problem of drug abuse is slowly gaining momentum in major urban centres. It is presumed to have a high prevalence in Mombasa and Nairobi Counties because of their City Status. This presumption is buttressed by past anecdotal media accounts of widespread use and (suspected) serious adverse drug reactions. These had led many women and religious groups to publicly protest, asking for better enforcement of the laws against some of these drugs (Browne-Miller, 2009). The opportunity for rational debate and effective policy making has also been limited. Policy measures that reflect such errors may be regarded as disproportionate and illegitimate by the sections of society that are the intended focus, which in turn could bring about unintended harmful consequences (Bivins, 2008). A country-wide needs assessment study undertaken by NACADA (2012) revealed that drug abuse has permeated all strata of Kenyan society, the youth and young adults being the most affected groups. New psychoactive substances pose a particular challenge to those formulating drugs' policy and related public health responses targeting these segments of the population (Bivins, 2008). While National Authority Campaign Against Alcohol and drug Abuse (NACADA) has made some progress in addressing alcohol and other drugs, little has been done to address new and emerging drugs. These drugs are eating into the very core of our society i.e. the youth, who prefer them to the mainstream and often criminalized illicit drugs (Evans-
Brown et al., 2011). Nairobi and Mombasa are ideal 'breeding grounds' for new and emerging drugs due to their demographics. Most emerging drugs e.g. shisha and kuber are associated with affluence or class that goes hand in hand with urban life (personal observation). Both counties have a cosmopolitan outlook that allows easy cross-pollination of ideas and cultures among different nationalities and racial as well as ethnic groups. Nairobi and Mombasa counties are home to a number of tourist attraction sites such as Nairobi National Park and Fort-Jesus respectively whose influence on cultural confluence cannot be underestimated. The location is particularly important in precipitating drug trade. Mombasa is home to Kilindini Harbour, Kenya's largest sea port and is a link to the Middle East through the Indian Ocean. Nairobi on the other hand is a link to the rest of the Sub Saharan and North African Countries through the land locked 'pearl of Africa' i.e Uganda through Busia and Malaba boarders. Lastly, recent reports (NACADA, 2012) and media accounts have been highlighting coastal drug problems especially in Mombasa County terming them as drowning. Scientists have generally categorized drugs of abuse into depressants, stimulants, hallucinogens, narcotics, and inhalants (Evans-Brown, et al., 2011). The emerging drugs or 'legal high' are combinations of the commonly abused drugs or precursor chemicals used as raw materials in the manufacture of various pharmaceutical products, and have the potential of being converted to illicit drugs. Despite these controls, misuse of pharmaceuticals can result from self-medicating, dependence, dealing with withdrawal symptoms, drug substitution, enhancing of other drugs or because a drug of choice is unavailable. Non-medical use of pharmaceutical drugs can result in serious health risks and can lead to addiction (DoHA 2011). Europe continues to see an increase in new synthetic substances with a total of 41 new synthetic psychoactive substances reported to the European Early Warning System in 2010 (Europol 2011). Of the 41 new psychoactive substances identified in 2010, 15 were synthetic cathinones and 11 were synthetic cannabinoids (EMCDDA 2011; Europol 2011). They are emerging as popular legal alternatives to alcohol, 
bhang, tobacco, miraa, heroin and cocaine among youths and are administered through drinking, snorting, smoking, inhaling, injecting, taken orally or applied on the skin (Young et al., 2010). However, there is limited or no data available on the new and emerging drugs,

\section{MATERIALS AND METHODS}

Study sites: The studies were conducted in selected districts within Mombasa and Nairobi County which were purposively selected based on drug prevalence and geographic location of rehabilitation centres. Mombasa and Nairobi County has a population of 938,370 and $3,138,369$, respectively (KNBS, 2009). Mombasa County is located on the South Eastern part of the Kenyan Coast where it borders the Indian Ocean to the East and South East, Kilifi County to the North and Kwale County to the West and South West. The County is the home to Kenya's largest sea-port, the trends, and prevalence in Kenya. Thus, the study was aimed to identify the new and emerging drugs, the trends and prevalence of their abuse in Mombasa and Nairobi County.

Kilindini Harbour and Mombasa international airport. The County serves as the major Centre for tourism industry. Four districts selected in Mombasa County were Mvita, Kisauni, Changamwe and Likoni. Nairobi County is the major Capital City of Kenya and is served by Jomo Kenyatta International Airport and Wilson Airport. It shares boundaries with Kiambu County to the North, Machakos County to the East, and Kajiado County to the South. The survey covered 4 Districts namely; Starehe, Westlands, Eastlands and Langata (Figure 1).

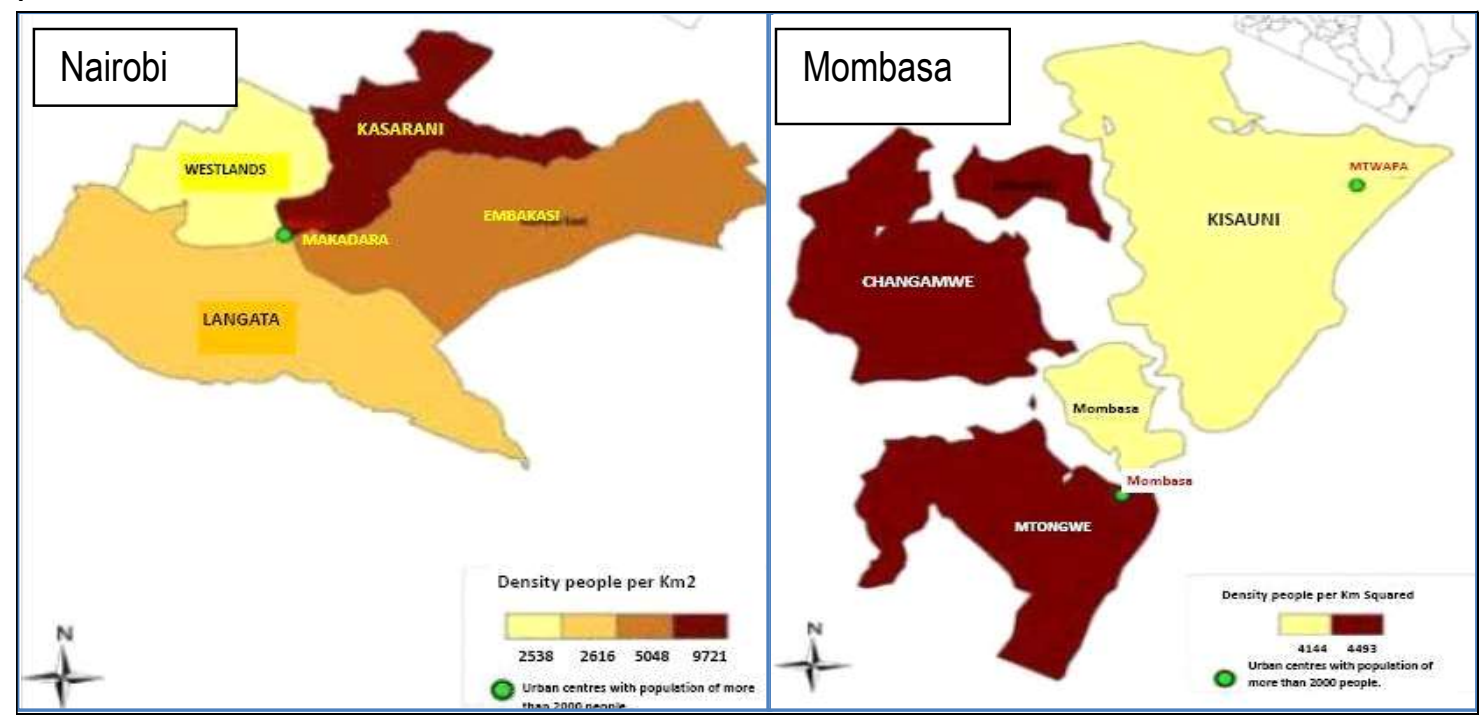

Figure 1: Maps of the Nairobi and Mombasa County

Sample and data collection: The study utilized an exploratory cross-sectional design where both quantitative and qualitative data was collected. Purposeful and snowball, a non-random sampling method was used to identify a potential respondents. This method is effective in locating members of special populations where the focus of the study is on a sensitive issue like drug abuse. Initial contacts were made through healthcare personnel, rehabilitation centres, welfare officers, faith-based organizations (FBOs), Non Governmental Organisations (NGOs) and the respondents who were asked to direct the research team to other persons according to the inclusion criteria. The respondents were interviewed using a structured questionnaire on emerging drugs and drug use. The interview captured issues on socio- demographic and socio-economic factors, emerging drug use and poly drug use among emerging drug users. To protect the privacy and confidentiality of the study participants, a secluded room or place was identified in each of the study sites where the subjects reported for interviewing purposes. The questionnaire was translated into Kiswahili to minimize the translation bias. Key informant interview was subjected to health care providers in the rehabilitation centres. Focus group discussions (FGDs were also carried out with questions targeting the different types of emerging drugs, socio-economic impacts among the users and strategies required to manage the problem of emerging drug use. These responses were used to supplement the findings of the study. The FGDs comprised 
of 8-10 participants who were emerging drug users. FGDs were tape-recorded with participants' consent. The questionnaires were checked by supervisors at the end of each day during the survey, for omissions and for coding responses.

Questionnaire: A questionnaire was developed by the team conducting the research for the purpose of addressing the objectives stated. Its aim was to collect information on the trends and prevalence of emerging drugs among the identified drug abusers. The questionnaire was used to collect the data after being pre-tested on 10 research assistants from Nairobi area.

Operational criteria: The respondents were included into the study if they were drug abusers between 10-65 years, residents of Nairobi or Mombasa for at least 6 months, and consented by signing to participate. Current abuser was defined as a respondent who had abused drugs for more than a month (30 days) prior to the survey.

Data analysis: Data was coded, entered, cleaned and analysed using SPSS software version 17, Excel, Stata and SAS software 2000. Descriptive statistics namely frequencies, pie chart, bar graphs and percentages were used to describe, organize and summarize collected data. The Pearson Correlation coefficient was used to establish the associations between categorical variables. Multivariate analysis was used to assess the independent predictors of

\section{RESULTS}

Social demographics: The research was conducted in Mombasa County where the respondents were 352 with females comprising of $33.8 \%$ and the males $66.2 \%$ and in Nairobi County where the respondents were 350 with females accounting for $22.9 \%$ and males $77.1 \%$. Most of the respondents were graduates of primary or secondary education. Nairobi had higher percentage with secondary education accounting for $46.9 \%$ followed by $41.7 \%$ with primary education. However, in Mombasa more respondents had primary education $(58.7 \%)$ followed by secondary education $(22.2 \%)$ and only $0.4 \%$ of the respondents from Nairobi had a degree. Most of the abusers were recorded in the age groups of 21-25 years, 26-30 years, 31-35 years and $36-40$ years in that order. Significantly higher percentage of abusers was recorded in Mombasa between 26- 30 years. Mombasa had abusers being recorded in the early and old age groups of 10-15 years and 55-60 years, respectively though the percentages were relatively low accounting for less than $3 \%$ of the respondents. Highest number of respondents was at $26-30$ years $(37.7 \%$ and $27 \%$ ) followed by $31-35$ years $(26.3 \%$ and $21 \%$ ) in Nairobi and Mombasa, respectively. It was observed that most of the abusers of emerging drugs in Mombasa were Muslims emerging drug use. Responses from open-ended questions, key informant interviews and FGDS were analysed qualitatively through content analysis. Logistic regression was preferred to linear probability models in analyzing due to the well-known shortcomings of the linear probability model especially the unlikeliness of the functional form when the response variable is highly skewed and suitability for predictions that are outside the $[0,1]$ bounds of probabilities (Caliendo and Kopeing, 2008). The probit regression model was preferred for comparison purposes. Some data was evaluated using a logistic regression model which was analyzed using Stata version 11.0 of 2009.

Ethical Consideration: Permission to carry out the study was sought from the relevant authorization bodies: Ethical clearance was obtained from Kenyatta University Ethics Review Committee and the National Council of Science and Technology. During administering of the questionnaires, respondents were informed that the information collected would be kept anonymous and the objective of the study was explained to the study participants. They were also briefed about the confidentiality of their responses and the importance of providing correct and accurate information, and that participation was voluntary. The respondents' signed the consent of providing the information. Anonymity, confidentiality and privacy of the study participants were safeguarded.

followed by Christians accounting for $56.3 \%$ and $38.8 \%$, respectively. However, in Nairobi Christians accounted for $73 \%$ while Muslims $18 \%$ of the total respondents. Buddhists in Mombasa comprised $2.6 \%$ of the total respondents. This survey also tried to identify the occupational status of the participants who abuse the emerging drugs. Various social grades and different careers were involved in the abuse of the emerging drugs. They ranged from Jua kali artisans, non-work, employed persons, sex workers, touts, students, self employed and thieves. Significant differences were observed on the number of respondents taking the emerging drugs between the type of occupation and within the county. In Mombasa County, the non working group were leading with $47.7 \%$ compared to $34.9 \%$ in Nairobi. In Nairobi County, Jua kali artisans were leading with $46.9 \%$ of the total respondents compared to $21.9 \%$ in Mombasa. The percentage of employed respondents abusing the emerging drugs was comparable in both counties accounting for $11.4 \%$ and $11.1 \%$ in Nairobi and Mombasa County, respectively. Significantly higher percentage of sex workers in Mombasa abused drugs compared to Nairobi County which accounted for $6.3 \%$ and $2.9 \%$, respectively. The students accounted for $4.0 \%$ and $1.4 \%$ of the total 
respondents in Mombasa and Nairobi County. A unique case of $0.9 \%$ of the night runners was recorded in Mombasa County.

Most of the abusers in both counties were found to be single people. Mombasa had significantly higher percentage of single persons abusing the emerging drugs than Nairobi, which accounted for $64 \%$ and $57 \%$, respectively. However the number of married persons abusing the emerging drugs was comparable in both Mombasa and Nairobi County, accounting for $26.1 \%$ and $24.3 \%$, respectively. Significantly higher percentage of divorced/separated persons in Nairobi abused the emerging drugs relative to Mombasa accounting for $20 \%$ and $7.1 \%$ respectively.

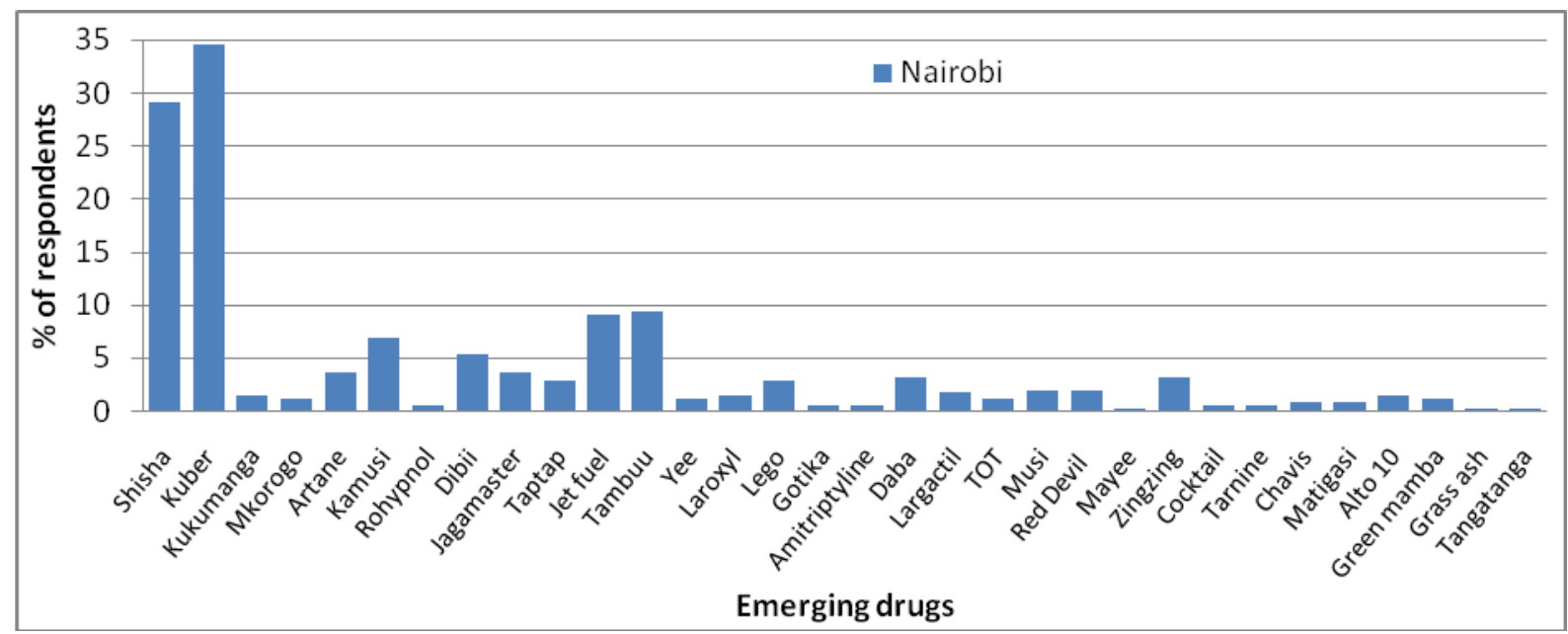

Figure 2: Emerging drugs in Nairobi County

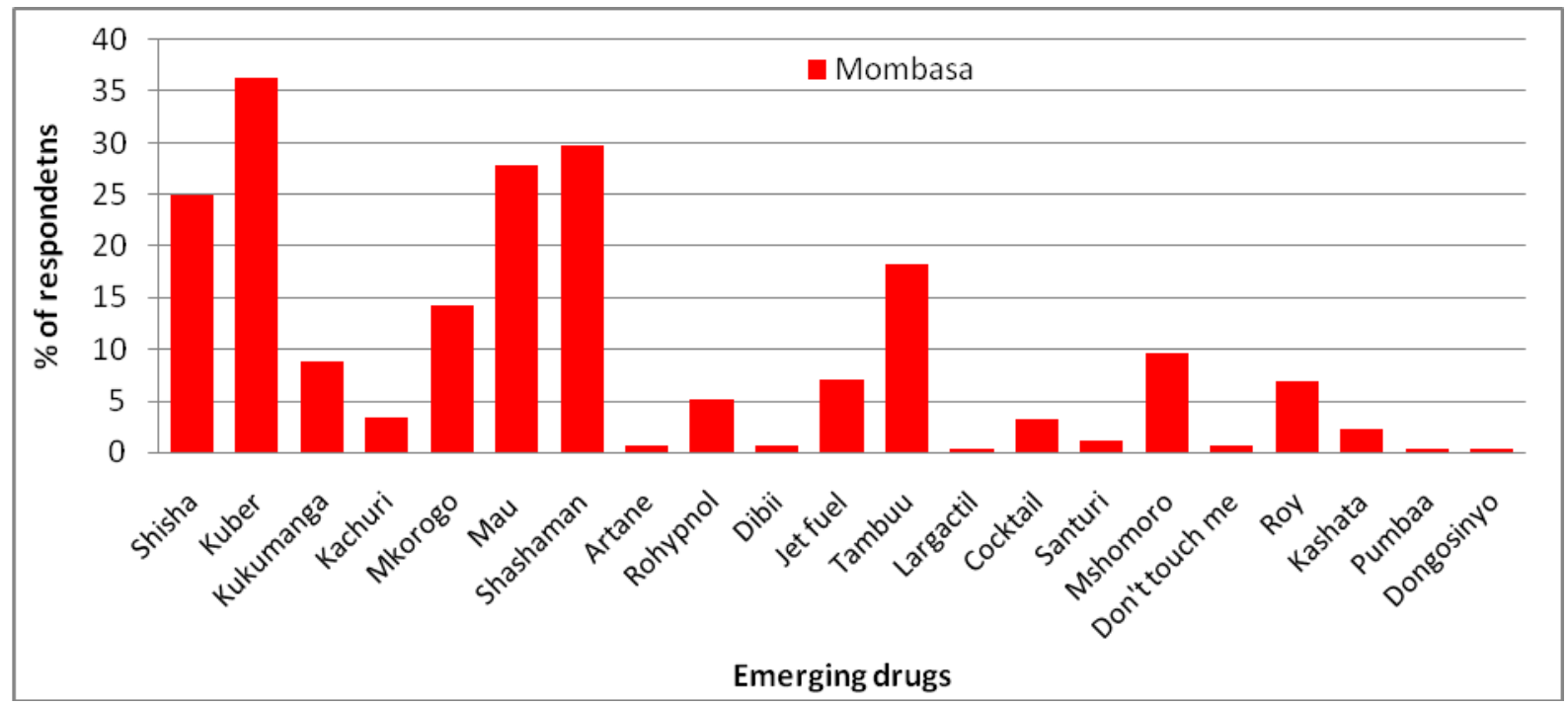

Figure 3: Emerging drugs in Mombasa County 


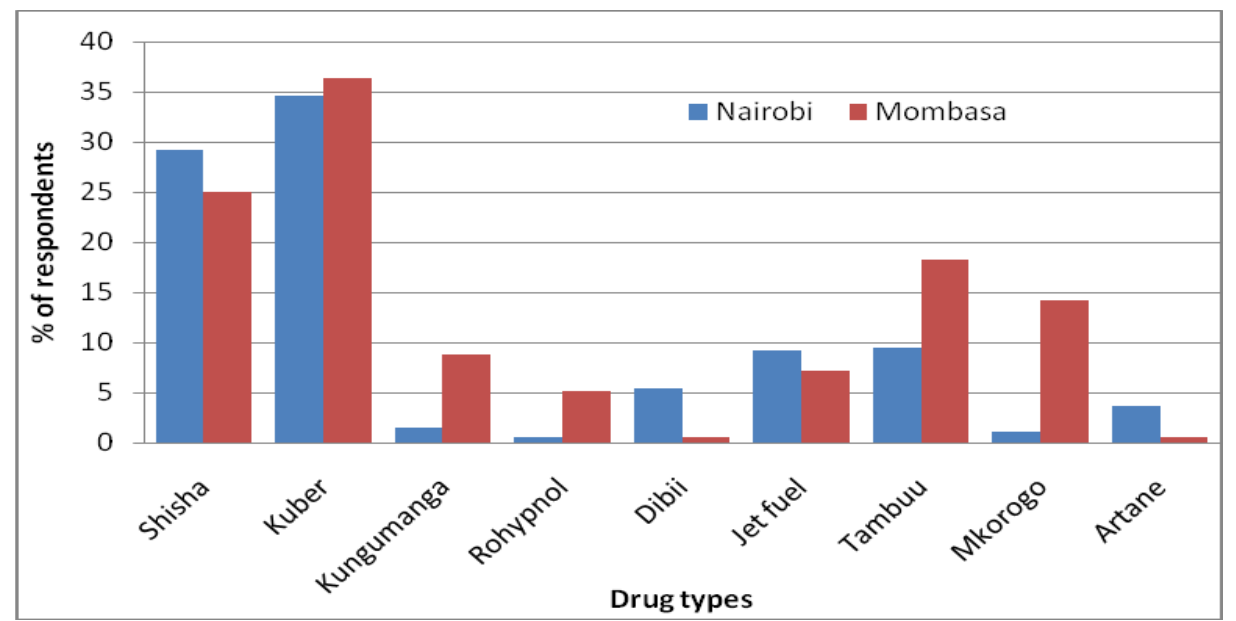

Figure 4: Commonly abused emerging drugs

Types of emerging drugs: About 40 different types of drugs were abused by the respondents. Number of emerging drugs was 32 and 21 in Nairobi and Mombasa, respectively. Some drugs were abused in isolation while others were a mixture of two, three or four types of drug (See Appendix 1). Most of the highly abused drugs were 'kuber, shisha, shashaman, mau, tambuu, jet fuel, kukumanga, mkorogo, mshomoro and kamusi and were common in both Nairobi and Mombasa County (Figure 2, 3, 4). Many were derivatives of bhang from different countries (shashaman from Ethiopia). Among the most commonly abused emerging drugs, Mombasa County recorded higher percentages than Nairobi except shisha which was higher in Nairobi. Most of the respondents took the emerging drugs due to lack of awareness while some people do not even think that the combinations were kinds of emerging drugs. Kuber and shisha were the most preferred drugs in both counties though the percentages varied between counties. Significantly higher number of respondents in Mombasa County abused Kuber than Nairobi County accounting for $21.2 \%$ and $15.4 \%$, respectively. However the abuse of shisha was comparable in both counties with $14.3 \%$ and $14 \%$ recorded in Nairobi and Mombasa County, respectively. Some of the drugs were unique within counties e.g. the drugs shashaman, mau, mkorogo were abused in Mombasa County only accounting $15.6 \%, 14.4 \%$ and $8.1 \%$, respectively.

Table 1: Comparison of districts and demographic factors on drug abuse

\begin{tabular}{lcccccc}
\hline \multicolumn{1}{c}{ Drugs } & Coef. & Std. Err. & $\mathrm{Z}$ & $\mathrm{P}>\mathrm{Z}$ & {$[95 \%$ Conf. } & Interval] \\
\hline Gender & 0.0238 & 0.03 & 0.71 & 0.48 & -0.04 & 0.09 \\
Religion & 0.0982 & 0.02 & 5.41 & $\mathbf{0 . 0 0}$ & 0.06 & 0.13 \\
Education & -0.0183 & 0.02 & -0.82 & 0.41 & -0.06 & 0.03 \\
Marital & -0.0099 & 0.02 & -0.47 & 0.64 & -0.05 & 0.03 \\
Occupation & 0.0099 & 0.01 & 0.94 & 0.35 & -0.01 & 0.03 \\
Nairobi & -0.1515 & 0.07 & -2.25 & $\mathbf{0 . 0 3}$ & -0.28 & -0.02 \\
Likoni & -0.0004 & 0.06 & -0.01 & 0.99 & -0.11 & 0.11 \\
Kisauni & 0.0384 & 0.06 & 0.67 & 0.50 & -0.07 & 0.15 \\
Changamwe & -0.0141 & 0.06 & -0.24 & 0.81 & -0.13 & 0.10 \\
Westland & 0.1786 & 0.07 & 2.72 & $\mathbf{0 . 0 1}$ & 0.05 & 0.31 \\
Langata & 0.1533 & 0.07 & 2.18 & 0.03 & 0.02 & 0.29 \\
Eastlands & 0.1682 & 0.07 & 2.50 & $\mathbf{0 . 0 1}$ & 0.04 & 0.30 \\
Age & -0.0132 & 0.01 & -1.11 & 0.27 & -0.04 & 0.01 \\
cons & 1.7755 & 0.10 & 18.41 & 0.00 & 1.59 & 1.96 \\
\hline
\end{tabular}

${ }^{*}$ Mombasa

*Mvita

*Starehe

$X^{2}(P)<0.00001$ 
Comparative studies were done using Poisson model and in Mombasa County, Mvita and Starehe were used as the base of the analysis. Religion had a significant effect of drug abuse of one abusing drugs. It was significantly less likely $(P=0.03)$ for people in Nairobi to abuse drugs than Mombasa County. There was no difference on the use of drugs in the three Districts of Mombasa County. However the level of drug use in Nairobi was significantly higher in Westlands,
Langata and Eastlands than Starehe Districts (Table 1). The high Pseudo $\mathrm{R}^{2}$ indicated goodness of fit for regression estimators meaning that there were relationships on the drug usage. The values of $R^{2}$ and Adjusted $R^{2}$ shown above for the analyzed data were within the accepted range and therefore showed that the model fitted well the predictor variables.

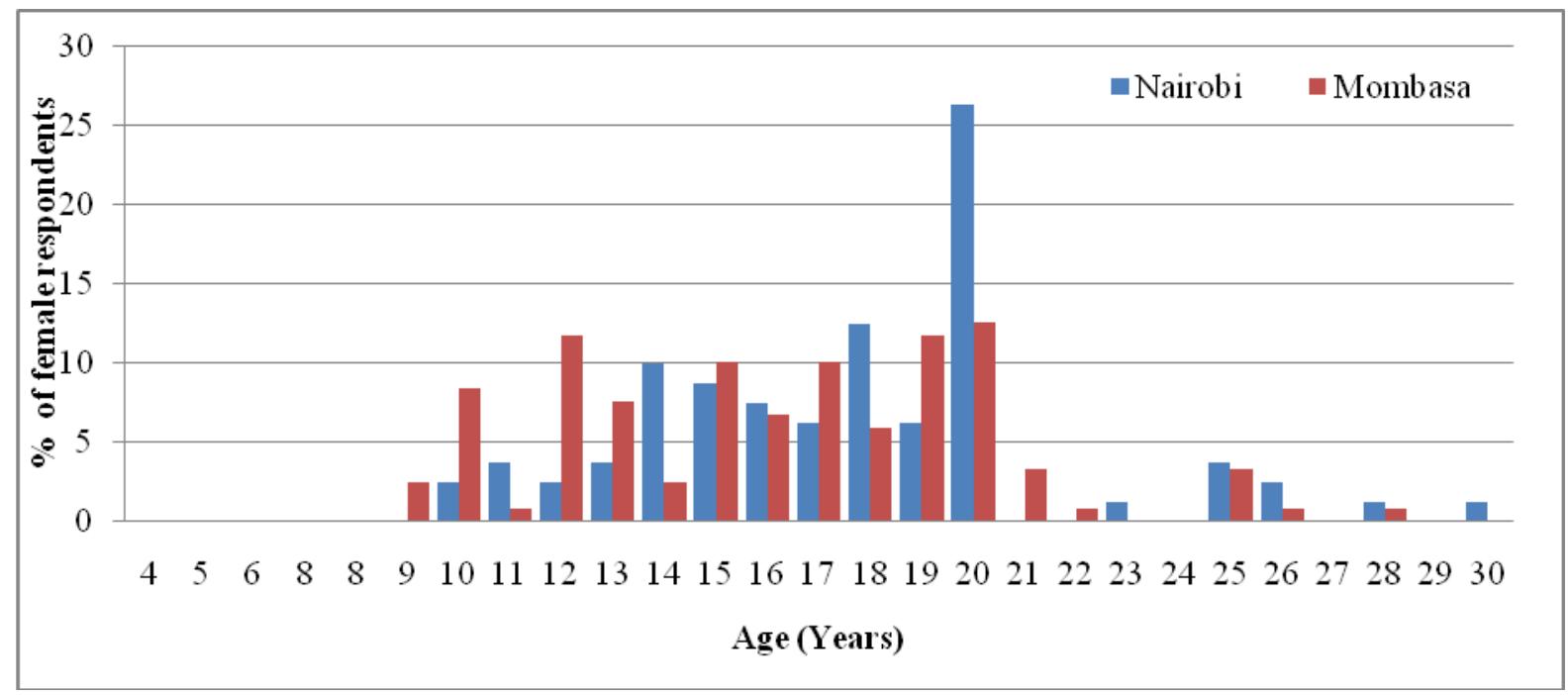

Figure 5: Comparison of initiation of females

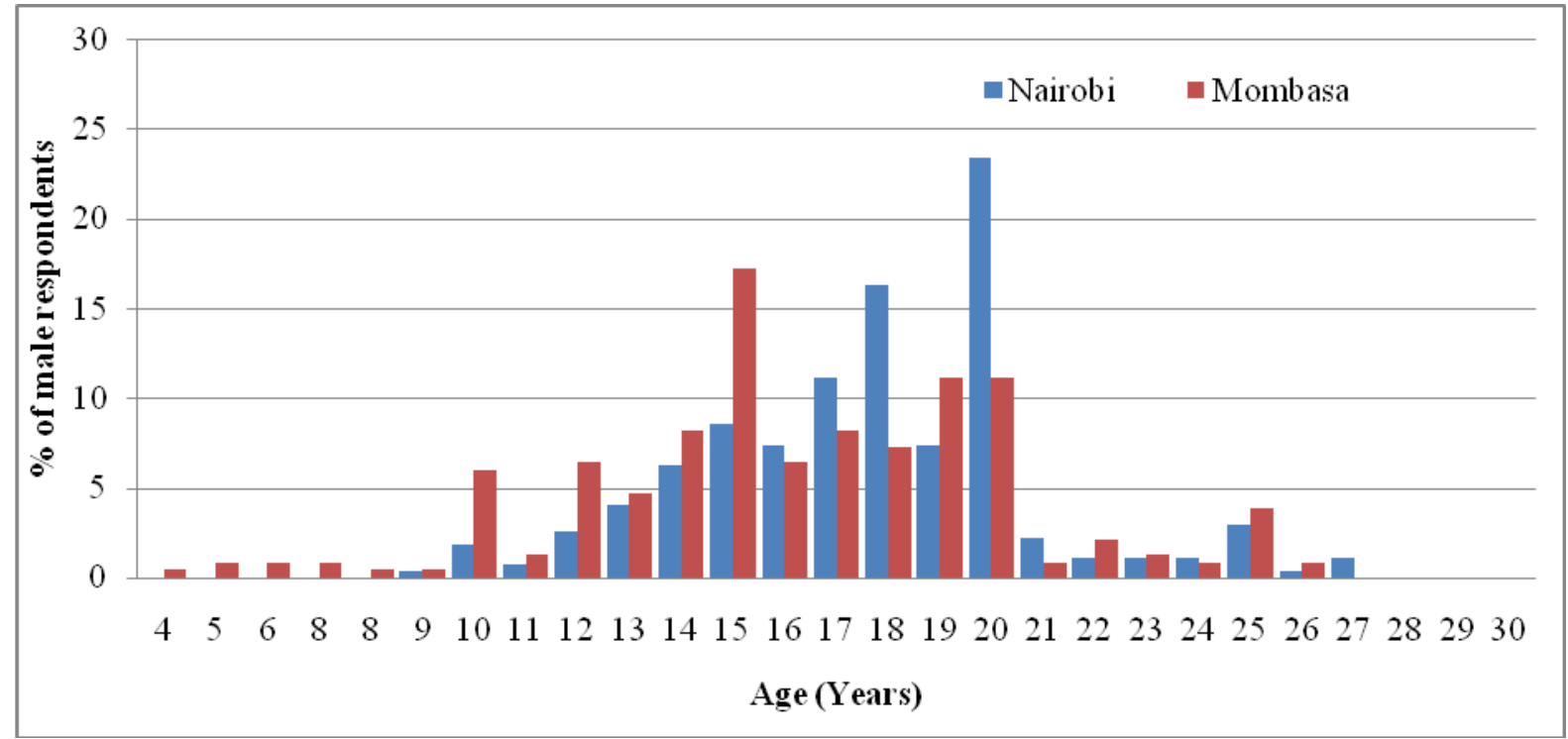

Figure 6: Comparison of Initiation of males

Initiation age of abusers: The average $( \pm S D)$ age of the sample of 350 and 352 respondents was $17.7 \pm 3.4$ years and $16.3 \pm 4.0$ years in Nairobi and Mombasa, respectively. Drug initiation age in Mombasa ranged from 4 year to 30 years contrary to Nairobi County which ranged from 9 years to 30 years. Mombasa had higher number of respondents initiated below the age of 15 years. However, the situation changed between 16 and 20 years. Ages 15 and 20 years 
recorded the highest number of youth initiated to drugs in Mombasa County (14.5\%) and Nairobi County (24\%). Mombasa had higher number of respondents initiated to drugs. Females were initiated to drugs at the age of 9 years in both Counties. $26.5 \%$ of the female respondents were initiated to drugs in Nairobi County compared to $12 \%$ in Mombasa County (Figure 5, 6).

Table 2: Modes of administration of drugs

\begin{tabular}{lcccc}
\hline & \multicolumn{2}{c}{ Nairobi } & \multicolumn{2}{c}{ Mombasa } \\
\cline { 2 - 5 } & Freq & Percent & 157 & Percent \\
\hline Chewing & 190 & 54.3 & 28 & 44.6 \\
Drinking & 139 & 39.7 & 245 & 8.0 \\
Smoking & 135 & 38.6 & 54 & 69.6 \\
Inhaling & 76 & 21.7 & 118 & 15.3 \\
Injecting & 9 & 2.6 & 15 & 33.5 \\
Snorting & 2 & 0.6 & 4.3 \\
\hline
\end{tabular}

Mode of administration: Smoking, drinking, chewing and injecting were the most preferred modes of administration. Significant difference was observed in all the modes of administration between Mombasa and Nairobi County. Significantly higher number of respondents from Mombasa County administered the drugs through smoking (69.6\%), injecting $(33.5 \%)$ and snorting (4.3\%) than Nairobi County. However, in Nairobi more respondents administered the drugs through chewing (54.3\%), drinking (39.7\%), smoking, $38.6 \%$ and inhalation (21.7\%) (Table 2).
Contribution factors to drug abuse: The respondents gave a number of reasons as to why they started abusing the emerging drugs. Peer pressure, curiosity, stress and frustration were identified as the most important factors that made the respondents start abusing the drugs. Peer pressure was the highest accounting for $72.4 \%$ and $52.7 \%$ in Nairobi and Mombasa, respectively. However other responses such as feeling good, acceptance, availability and cheapness (Cost of the substance) varied between the counties as reasons (Figure 7).

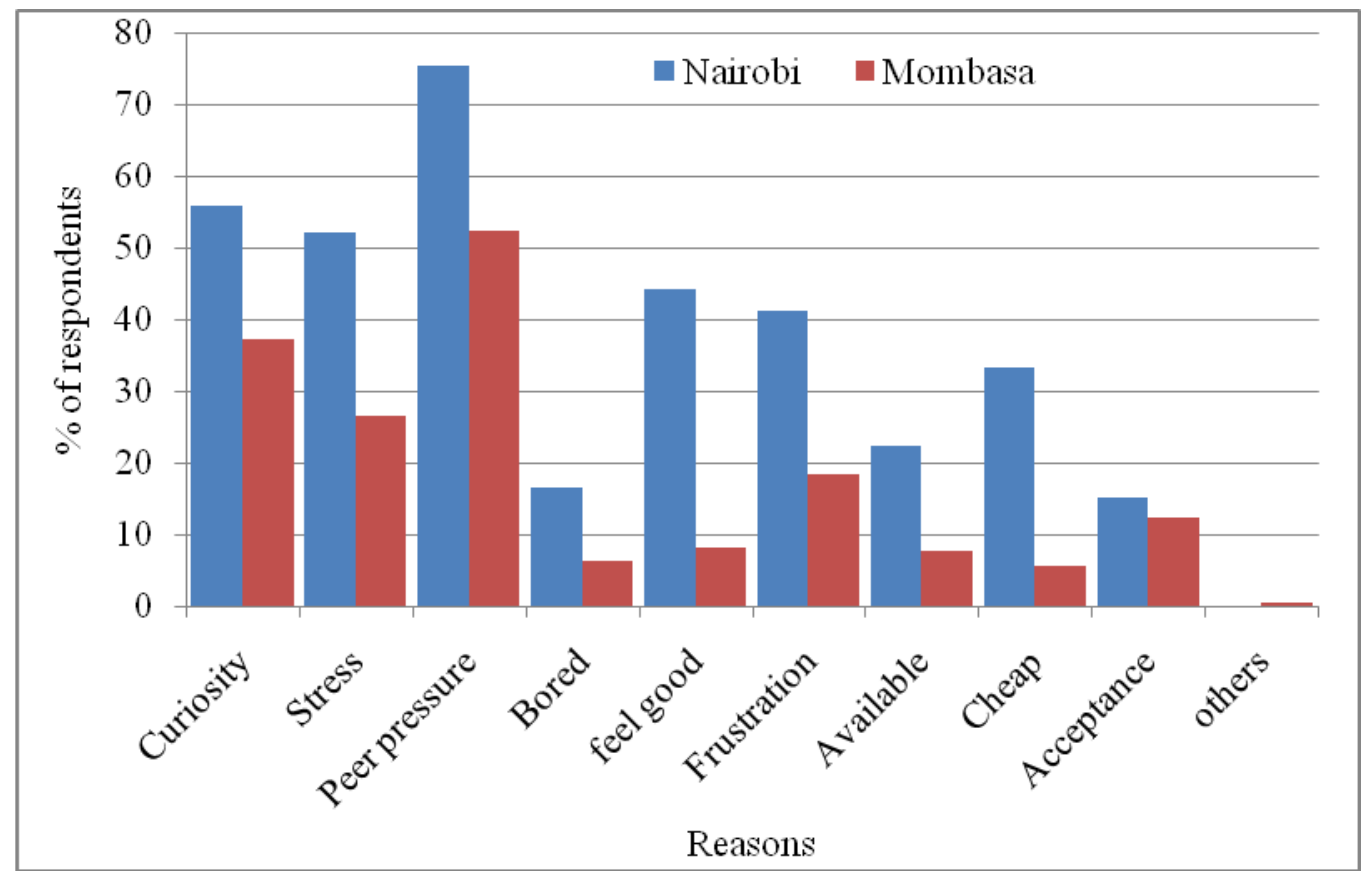

Figure 7: Reasons for drug abuse 
Introduction and source of information on drugs: Friends had a lot on influence on the respondents taking the drugs accounting for $90.6 \%$ (SD \pm 0.29 ) and $76.7 \%$ (SD \pm 0.42 ) in both Nairobi and Mombasa, respectively. Influence by friends in Nairobi was significantly higher than Mombasa. This was followed by self $(26.5 \%$ in Nairobi and $15.5 \%$ in Mombasa (Table 3). The large number of the respondents who learnt through self could have been due to media, family exposure and even the internet or other channels. Most of the respondents learnt about drugs from friends who accounted for $93.9 \% \pm 0.29$ (Std. Dev.) in Nairobi and $84.8 \% \pm 0.42$ (Std. Dev.) in Mombasa County. Internet had no influence on abuse of emerging drugs and accounted for only $0.2 \%$ and $0.3 \%$ in Nairobi and Mombasa, respectively.

Table 3: Response on introduction to drugs

\begin{tabular}{lcccc}
\hline & \multicolumn{3}{c}{ Nairobi County } & \multicolumn{3}{c}{ Mombasa County } \\
\cline { 2 - 5 } & Percent & Std. Dev. & Percent & Std. Dev. \\
\hline Friends & 90.6 & 0.29 & 76.7 & 0.42 \\
Self & 26.6 & 0.44 & 7.9 & 0.27 \\
Relatives & 12.9 & 0.33 & 15.3 & 0.36 \\
Workmates & 3.1 & 0.17 & 8.5 & 0.28 \\
Family & 2.3 & 0.15 & 6.3 & 0.25 \\
Others & 0.29 & 0.05 & 2.0 & 0.14 \\
\hline
\end{tabular}

Sources of drugs: A number of outlets selling the emerging drugs are on the increase. Most of the drugs were purchased or outsourced from the streets. Significantly higher number of participants in Nairobi (92\%) obtained their drugs from the streets than Mombasa (61.9\%). However, $42 \%$ obtained drugs from the smart shops in Mombasa compared to $8.9 \%$ in Nairobi County. The selling of emerging drugs on the streets and smart shops posed a common threat of reaching the unintended age group especially the young children. Nevertheless some outlets such as streets, smart shops, chemists and general shops were evidenced in enhancing the availability and accessibility of emerging drugs by providing their services in nearby vicinities and by operating at all times.
Place of drug consumption: The hot spots of emerging drugs ranged from public entertainment places to more private and more secret sites, such as dens, nightclubs, hotels, rental houses. Most of the drugs were consumed in the drug dens accounting for $87.1 \%$ and $82.1 \%$ in Nairobi and Mombasa, respectively followed by clubs, parties and homes. Consumption of the drugs was low in schools (Table 4). Entertainment places had become drug-infested place and this could be motivated by the high profit from drugs, owners sometimes connive drug-abusing. It was noted that most of the respondents preferred abusing the drugs in the company of friends, in groups or alone. In the company of friends accounted for $89.7 \%$ and $78.7 \%$, groups $(12 \%$ and $14.8 \%)$ and alone (41.4\% and $21 \%$ ) in Nairobi and Mombasa, respectively.

Table 4: Venue of drug abuse

\begin{tabular}{|c|c|c|c|c|}
\hline & \multicolumn{2}{|c|}{ Nairobi County } & \multicolumn{2}{|c|}{ Mombasa County } \\
\hline & Mean & Std. Dev. & Mean & Std. Dev. \\
\hline Social club & 58.9 & 0.49 & 39.2 & 0.49 \\
\hline Drug dens & 87.1 & 0.34 & 82.4 & 0.39 \\
\hline Schools & 1.7 & 0.13 & 3.7 & 0.19 \\
\hline Workplace & 12.6 & 0.33 & 10.5 & 0.31 \\
\hline Party & 36.0 & 0.48 & 17.6 & 0.38 \\
\hline Home & 0.0 & 0.00 & 11.1 & 0.31 \\
\hline Other & 2.0 & 0.14 & 4.5 & 0.21 \\
\hline
\end{tabular}

Perception on likeability, accessibility and affordability of emerging drugs: The quick high effect, lasting high, affordability and accessibility were the major reasons why the respondents abused the emerging drugs. Most of the respondents preferred abusing the emerging drugs due to their 'quick high' producing a marked psychoactive effects 
accounting for $56.3 \%$ and $55.7 \%$ in Nairobi and Mombasa Counties, respectively. This was followed by lasting high effect in Mombasa (42.9\%) and affordability in Nairobi (29.6\%). Easy access of the drugs from the streets, drug stores, chemists made the respondents abuse them. Others abused the drugs because it was fashionable and easy to administer. Some respondents were attracted to the drugs by its alleged legal status of emerging drugs. Increased availability was positively associated with increased use (Table 5).

Table 5: Likeability of emerging drugs

\begin{tabular}{lcccc}
\hline & \multicolumn{2}{c}{ Nairobi } & \multicolumn{2}{c}{ Mombasa } \\
\cline { 2 - 5 } & Percent & Std. Dev. & Percent & Std. Dev. \\
\hline Quick high & 56.3 & 0.50 & 55.7 & 0.50 \\
Lasting high & 23.4 & 0.42 & 42.9 & 0.50 \\
Affordability & 26.9 & 0.44 & 8.0 & 0.27 \\
Accessible & 10.3 & 0.30 & 8.2 & 0.28 \\
Legal & 0.6 & 0.08 & 2.6 & 0.16 \\
Administer & 1.4 & 0.12 & 2.6 & 0.16 \\
Fashionable & 2.6 & 0.16 & 3.1 & 0.17 \\
Induce sleep & 0.9 & 0.09 & 0.6 & 0.08 \\
Sex inducing & - & - & 3.7 & 0.19 \\
Extra strength & - & - & 3.1 & 0.17 \\
Stay awake & - & - & 0.6 & 0.08 \\
\hline
\end{tabular}

The study revealed that the drugs were readily available and accessible in many outlets such as clubs, streets, and drug dens. Relatively, Mombasa had higher accessibility and availability of emerging drugs than Nairobi. Most of the respondents felt that the emerging drugs were readily accessible accounting for $98 \%$ and $87 \%$ in Nairobi and Mombasa respectively. Respondents in both counties were of the opinion that the drugs were affordable and quite affordable. In Nairobi, $39.7 \%$ said that the prices of the drugs were quite affordable while $50.6 \%$ said they were affordable while in Mombasa $21 \%$ said it was quite affordable and $65.9 \%$ affordable. There was a positive relationship between accessibility and affordability of drugs in both counties. Significant positive correlation of $(r=0.67, P<0.0001)$ was observed between accessibility and affordability of drugs in Mombasa county. According to the interviewed consumers, larger proportion of the respondents spent an average of Kshs $200-500$ per day with Mombasa having $38.9 \%$ while Nairobi $59.7 \%$ of the respondents. It was observed that $25.9 \%$ and $1.1 \%$ of the respondents spent over Kshs 1000 (USD 12) per day in Mombasa and Nairobi, respectively. Most of the money in both counties was from their own sources, accounting for $97.1 \%$ in Nairobi and $65.9 \%$ in Mombasa County, followed by money from friends and parents. In Mombasa a few cases got their drug money from stealing and the females from commercial sex. Use of Kshs 500-1,000 (USD 6-12) per day translated to about Kshs $15,000-30,000$ (USD 176-353) per month, which is quite an amount to spend on drugs considering most of the respondents were not employed. That could be the reason why some had to steal while others earned their money for drugs through prostitution. This was positively related to the types of drugs consumed in the county.

Combination and substitution of drugs: It was observed that the emerging drugs were mostly taken in combination with the usual drugs. Various emerging drugs combining bhang were the most abused accounting for $40.8 \%$ and $35.9 \%$ in Mombasa and Nairobi, respectively followed by chang'aa (31\% and heroin (29.6\%) in Mombasa and tobacco $(25.8 \%)$ and chang'aa (25.3 \%) in Nairobi (Table 6). Mixing of heroin with the emerging drugs was significantly higher in Mombasa than Nairobi. Combination of emerging drugs with cocaine was the least accounting for less than $3 \%$ in both Counties. Though alcohol is readily available only $11.1 \%$ and $2.7 \%$ in Nairobi and Mombasa combined the emerging drugs with alcohol. Similar observations were made on miraa though the percentages were relatively higher than alcohol. Heroin and cocaine that were used in combination of other drugs were reported to be affordable. 
Table 6: Combination of emerging drugs with other drugs

\begin{tabular}{rcccc}
\hline & \multicolumn{2}{c}{ Nairobi County } & \multicolumn{2}{c}{ Mombasa County } \\
\cline { 2 - 5 } & Percent & Std. Dev. & Percent & Std. Dev. \\
\hline Emerging drugs & 22.9 & 0.42 & 27.8 & 0.45 \\
Bhang & 23.1 & 0.42 & 33.2 & 0.47 \\
Changaa & 21.7 & 0.41 & 19.9 & 0.40 \\
Tobacco & 17.4 & 0.38 & 15.1 & 0.36 \\
Miraa & 14.0 & 0.35 & 8.5 & 0.28 \\
Heroin & 11.7 & 0.32 & 24.1 & 0.43 \\
Alcohol & 7.4 & 0.26 & 2.0 & 0.14 \\
Cocaine & 0.3 & 0.05 & 0.9 & 0.09 \\
Others & 17.4 & 0.38 & 5.1 & 0.22 \\
\hline
\end{tabular}

Table 7: Drugs substituted with EDs in Nairobi and Mombasa County

\begin{tabular}{lrrrc}
\hline & \multicolumn{2}{c}{ Nairobi County } & \multicolumn{2}{c}{ Mombasa County } \\
\cline { 2 - 5 } & Percent & Std. Dev. & Percent & Std. Dev. \\
\hline Alter EDs & 17.7 & 0.38 & 15.3 & 0.36 \\
Tobacco & 25.7 & 0.44 & 19.6 & 0.4 \\
Changaa & 18.3 & 0.39 & 8.8 & 0.28 \\
Heroin & 15.7 & 0.36 & 27.8 & 0.45 \\
Bhang & 13.1 & 0.34 & 28.4 & 0.45 \\
Miraa & 5.4 & 0.23 & 4.3 & 0.2 \\
Alcohol & 4.6 & 0.21 & 2.8 & 0.17 \\
Cocaine & 0.9 & 0.09 & 1.7 & 0.13 \\
Morphine & 0.3 & 0.05 & - & - \\
Other & 24.9 & 0.43 & 6.3 & 0.24 \\
\hline
\end{tabular}

Other than combining the drugs, it was also noted that in some cases the participants substituted the mainstream drugs with the emerging drugs. The emerging drugs were sourced to substitute mainly bhang, heroin, tobacco and chang'aa. It was observed that Mombasa had higher preference on substitutions of mainstream drugs with emerging drugs than Nairobi. The ranking of the substitutions done were $(28.4 \%)$ bhang and $(27.8 \%)$ heroin and $(19.6 \%)$ tobacco in Mombasa, and (25.7\%) tobacco,
$(18.3 \%)$ chang'aa and $(15.7 \%)$ heroin in Nairobi. Significantly low numbers of the respondents substituted miraa and alcohol with the emerging drugs in both Mombasa and Nairobi though they are readily available and legal (Table 7). As observed earlier on the combinations of emerging drugs with the commonly abused drugs, relatively low numbers substituted Cocaine with emerging drugs. This may be associated to the greater dependency on cocaine as well as easier accessibility of cocaine. 
Table 8: Prescription medicine

\begin{tabular}{lccccc}
\hline & \multicolumn{3}{c}{ Nairobi } & \multicolumn{3}{c}{ Mombasa } \\
\cline { 2 - 6 } & Freq & Percent & Freq & Percent & Std. Dev. \\
\hline Valium & 145 & 41.4 & 61 & 17.3 & 17.04 \\
Panadol & 103 & 29.4 & 44 & 12.5 & 11.97 \\
Artane & 27 & 7.7 & 10 & 2.8 & 3.45 \\
Rohypnol & 22 & 6.3 & 43 & 12.2 & 4.19 \\
Piriton & 17 & 4.9 & 35 & 9.9 & 3.60 \\
Laroxly & 10 & 2.9 & - & - & 2.02 \\
largactil & 4 & 1.1 & - & - & 0.81 \\
Serepax & 5 & 1.4 & 2 & 0.6 & 0.61 \\
Tap tap & 1 & 0.3 & - & - & 0.20 \\
Amoxy1 & 6 & 1.7 & 3 & 0.9 & 0.61 \\
Morphine & 1 & 0.3 & - & - & 0.20 \\
Codeine & 1 & 0.3 & 7 & 2.0 & 1.20 \\
Methadone & - & - & 13 & 3.7 & 2.61 \\
Diclophenac & - & - & 17 & 4.8 & 3.42 \\
ARVs & - & - & 8 & 2.3 & 1.61 \\
\hline
\end{tabular}

Respondents from Nairobi County abused prescription medicine more than Mombasa. The prescription drugs commonly abused included pain relievers, tranquilizers, sedatives and stimulants. Morphine, heroin and codeine belong to the group of opiates. Some of the prescription medicines abusers in the order of importance in Nairobi were Valium $\AA$, Panado $₫$, Artane $₫$, Rohypnol $₫$, Cozapam, and Piriton ${ }^{\circledR}$ while Mombasa had Valium, Rohypnol, Panadol, Piriton, Diclofenac $®$ and Methadone. Methadone is a synthetic opioid pain reliever, similar to morphine which is used to reduce withdrawal symptoms in people addicted to heroin or other narcotic drugs without causing the "high" associated with the drug addiction. Methadone is used as a pain reliever and as part of drug addiction detoxification and maintenance programs. Cozapam and Largactil were only abused by respondents in Nairobi while Diclofenac, Methadone and antiretroviral drugs (ARVs) used by patients with AIDs to control HIV infection were abused only in Mombasa (Table 8). Valium abuse accounted for $(41.4 \%$ and $17.3 \%)$ followed by Panadol (29.4\% and $12.5 \%)$ and Rohypnol (6.3\% and 12.2\%) in Nairobi and Mombasa, respectively

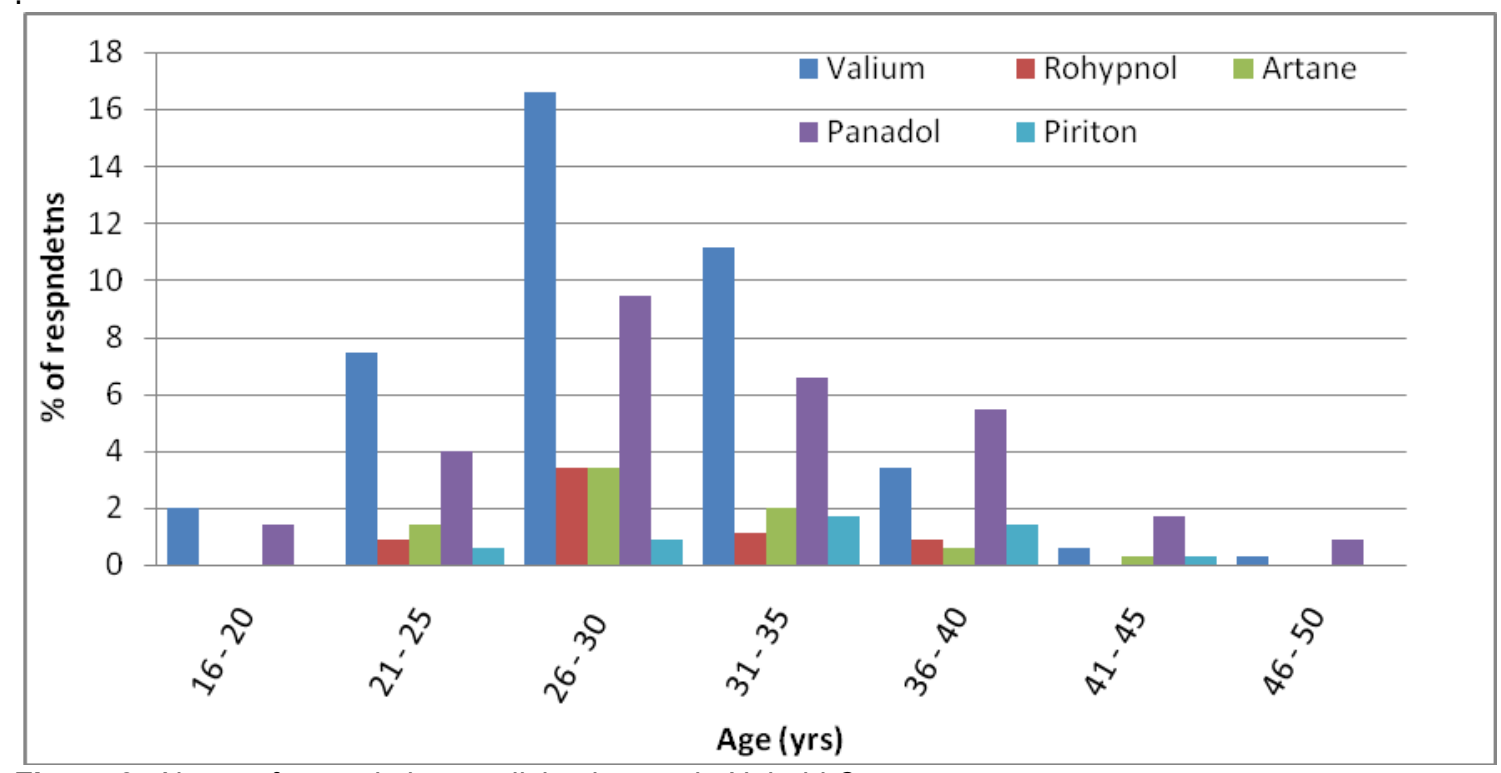

Figure 8: Abuse of prescription medicine by age in Nairobi County 


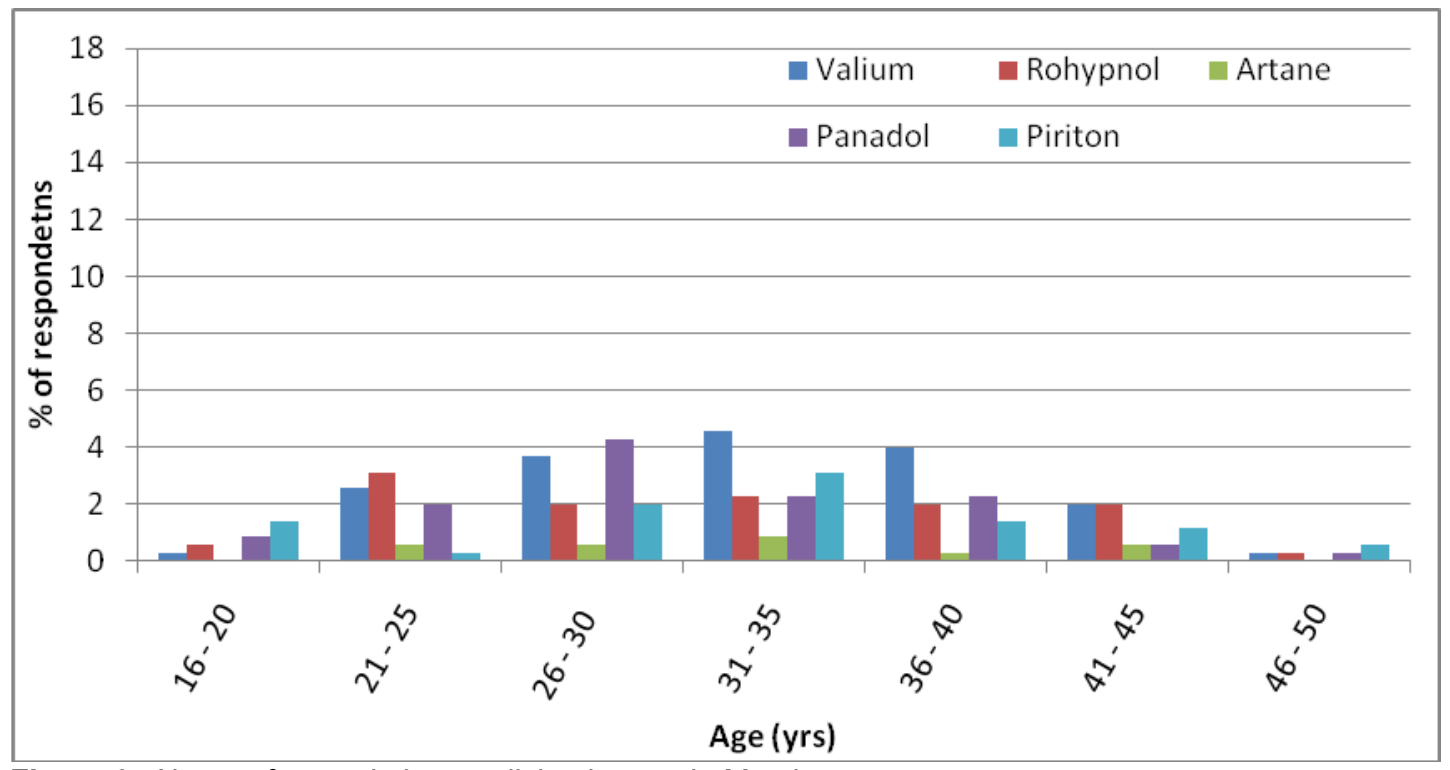

Figure 9: Abuse of prescription medicine by age in Mombasa

Upon comparing the age groups in the two counties, age 2630 years had the largest number of prescription medicine abusers. Higher number of Valium abusers in the age group (26-30 years) was found in Nairobi accounting for $16.6 \%$ followed by panadol at $9.4 \%$ while $31-35$ years had $11.1 \%$ of valium abusers. However, in Mombasa age 31-35 years abused valium more (4.5\%) (Figure 8 and 9 ).

Effects of drug abuse: Generally drugs had a numerous effects on the individual abuser, the family, community and the country at large. They included health, social, economic and political effects. Many felt that drug abuse lead to stigmatization of the addicts from the family and community, many suffered from loss of finances through purchasing of drugs or being sacked from their workplace. A number of addicts suffered from serious withdrawal symptoms especially when they were not able to purchase the drugs or when drugs were not available. Some of the respondents complained of getting addicted to drugs while others suffered from problems of feeling lethargic and lazy. The respondents agreed that the emerging drugs had a lot of impact on the county security, economy, education, drop-out rate in schools, non performance at the work place and reproductive health. Over $90 \%$ of the respondents in Nairobi agreed on the problems while in Mombasa around 70-80\% positively agreed that drugs had a lot of impact on the issues raised (Table 9 and 10).

Table 9: Problems encountered as a result of drug abuse

\begin{tabular}{lcccc}
\hline & & Nairobi & \multicolumn{2}{c}{ Mombasa } \\
\hline Drug conflict & Percent & Std. Dev. & Percent & Std. Dev. \\
Conflict family & 98.6 & 0.12 & 76.4 & 0.43 \\
Accidents & 96.0 & 0.20 & 87.2 & 0.33 \\
Police problems & 94.6 & 0.23 & 74.1 & 0.44 \\
Health problem & 94.0 & 0.24 & 80.7 & 0.40 \\
Arrest & 87.4 & 0.33 & 71.0 & 0.45 \\
\hline
\end{tabular}


Table 10: Social economic effects of emerging drugs

\begin{tabular}{rrrr}
\hline & Nairobi & Mombasa & Std. Dev. \\
Security & 83.4 & 51.1 & 22.8 \\
Economy & 87.7 & 54.8 & 23.3 \\
Education & 81.4 & 74.4 & 4.9 \\
School drop out & 85.4 & 53.4 & 22.6 \\
Non performance at work & 77.4 & 51.1 & 18.6 \\
Reproductive health & 74.9 & 48.6 & 18.6 \\
Other sector & 11.4 & 6.0 & 3.9 \\
\hline
\end{tabular}

Table 11: Other ADA related issues

\begin{tabular}{llccc}
\hline \multirow{2}{*}{ Other issues } & \multicolumn{3}{c}{ Nairobi } & Mombasa \\
\cline { 2 - 5 } & Response & Percent & Percent & Std. Dev. \\
\hline ADA is a private affair & Agree & 8.3 & 46.9 & 27.25 \\
& Disagree & 87.8 & 46.9 & 28.92 \\
& Nor sure & 1.1 & 6.3 & 3.63 \\
\hline Effect of ADA on health & Agree & 98.3 & 83.2 & 10.64 \\
& Disagree & 1.1 & 12.8 & 8.23 \\
& Not sure & 0.6 & 4.0 & 2.41 \\
\hline Does ADA affect County & Agree & 98.0 & 89.2 & 6.22 \\
& Disagree & 0.3 & 5.7 & 3.82 \\
& Not sure & 1.7 & 5.1 & 2.40 \\
\hline Addiction is a disease & Agree & 99.1 & 86.1 & 9.24 \\
& Disagree & 0.6 & 4.8 & 3.01 \\
& Not sure & 0.3 & 9.1 & 6.23 \\
\hline
\end{tabular}

Over $50 \%$ of the respondents visited the hospitals or health facilities in the last one month or one year. It was observed that most of the respondents were willing to stop abusing the drugs at $96.9 \%( \pm 0.17)$ and $86.9 \%( \pm 0.34)$ in Nairobi and Mombasa, respectively. Many disagreed that ADA is a private affair with $87 \%$ and $46 \%$ in Nairobi and Mombasa, respectively. Most were in agreement that ADA affected individual's health, affected the county and addiction was a disease (Table 11).

Family related issues: Other family members also abused various drugs. They included the parents, spouses, and siblings. Amongst the siblings, brothers were abusing more with $30.1 \%$ and $28 \%$ registered in Mombasa and Nairobi, respectively. The members were known to abuse most of the commonly abused drugs and the preference differed between the Counties. Abuse of Changaa was higher in
Nairobi than Mombasa while miraa was higher in Mombasa. Abuse of both heroin and cocaine was higher in Mombasa while alcohol was higher in Nairobi.

Interventions to curb drug abuse: The abusers were aware of the dangers faced in drug abuse and suggested a number of interventions they thought would really help them get out of drug abuse. The respondents from Nairobi County felt very strongly on the need of interventions with over $60 \%$ being recorded on each intervention. They strongly felt that the Government should set up rehabilitation centres, start training programmes on ADA, establish Employee Assistant Programmes (EAPs, setup wellness centres, control selling of prescription drugs and even fixing stiff penalties on the drug peddlers and banning of advertisement on media among others (Table 12). 
Table 12: Types of interventions to curb emerging drugs and abuse

\begin{tabular}{rccc}
\hline & Nairobi & Mombasa & Std. Dev \\
\hline Treatment and rehab centres & 96.3 & 87.5 & 6.2 \\
Training programs on ADA & 77.4 & 42.9 & 24.4 \\
Put up posters & 78.6 & 24.1 & 38.5 \\
Wellness centres & 78.0 & 18.8 & 41.9 \\
Assistance programs & 73.1 & 42.3 & 21.8 \\
Stiff penalties on peddlers & 71.7 & 42.0 & 21.0 \\
Control sale of medicine & 64.0 & 24.1 & 28.2 \\
Employee Assistant Prog. (EAPs) & 65.4 & 36.6 & 20.4 \\
Ban advertising & 63.1 & 21.6 & 29.4 \\
Other interventions & 2.9 & 1.7 & 0.8 \\
\hline
\end{tabular}

Table 13: Respondents sharing needles in Nairobi and Mombasa County

\begin{tabular}{|c|c|c|c|c|}
\hline \multicolumn{5}{|c|}{ Heroin needle exchange } \\
\hline Nairobi & Response & No & Yes & Total \\
\hline & No & 267 & 12 & 279 \\
\hline & Yes & 23 & 48 & 71 \\
\hline & Total & 290 & 60 & 350 \\
\hline & & $x^{2}=161$ & & $P<0.0001$ \\
\hline \multirow[t]{5}{*}{ Mombasa } & Response & No & Yes & Total \\
\hline & No & 132 & 25 & 157 \\
\hline & Yes & 57 & 138 & 195 \\
\hline & & 198 & 163 & 352 \\
\hline & \multicolumn{2}{|c|}{$x^{2}=105.593$} & \multicolumn{2}{|c|}{$P<0.0001$} \\
\hline
\end{tabular}

Other issues that were raised included building of more treatment and rehabilitation centres, provision of employment, introduction of stiff penalties on the drug peddlers and decriminalise drug addiction. A few of the key informants and the Focus Group Discussions (FGDs) felt that there is need to provide the addicts with clean needles and syringes as this would reduce on needle sharing and reduce on the prevalence of HIV and AIDS especially in Mombasa county where most of the abusers share needles when injecting heroin and cocaine (Table 13).

\section{DISCUSSIONS AND CONCLUSIONS}

From the survey conducted from 702 respondents from Nairobi and Mombasa counties, it is quite clear that there are many new and emerging drugs in the country. A total of 42 drugs were reported with Nairobi County recording higher numbers than Mombasa. This could be due to internet access and the higher level of education of respondents. The number of these new drugs has risen from 13 in 2008 to more than 70 , while the number of websites selling them has rocketed from 170 to 690 in the last two years (EMCDDA, 2013; http://www.thisissouthwales.co.uk). Some of the factors leading to the rapid growth in use of the emerging drugs are the fact that they are legal and readily available and easy to get hold of on the streets, smart shops, chemists, convenience stores and on the Internet. The respondents also stated that the emerging drugs gave them what they called 'a High' and a 'longer high' with less consumption. From the research findings many young people are using the emerging drugs to get 'a quick high' with less money. The drugs were also highly accessible, affordable, touted as legal and perceived as safe. They evade drug testing and 
are inadvertently promoted through media attention. Similarly, in Europe it was observed that many young people turn to alternative or synthetic drugs because of a belief that they're a legal substitute for popular street drugs and are more readily available through legitimate sources, such as gas stations, convenience stores, gardening/plant stores and online. They're also frequently thought to be safer than harder drugs. The rapid rise in their popularity is also attributed to Internet accessibility and information.

Our concerns with most of these new drugs revolves around the fact that they have not been in use long enough for researchers to be able to assess their long-term health effects on the abusers. Similar statements were expressed in the Major Swansea conference on legal highs and new and emerging drugs (2013) and also by National Institute of Drug Abuse (NIDA) http://www.thisissouthwales.co.uk. This is because some act as substitutes of opiods and cathinones and work in the brain as stimulants, depressants or hallucinogens. Some of the prescription drugs abused by the respondents were opioid pain relievers, stimulants and depressants for relieving anxiety or hallucinogens (Psychedelics). Those abusing the prescription and Over The Counter (OTC) drugs were aware of their addictive effects and they were at risk of adverse health effects if taken together with other drugs or alcohol. From the survey, it was noted that most of them were combining the prescription medicine with the emerging drugs and/or alcohol. Research shows that the opioids are particularly dangerous, especially when they are snorted or injected or combined with other drugs or alcohol (NIDA, 2013). The shisha is usually filtered using water, bhang or cocaine depending on the customer's preference. The great danger is that no information is available on what chemicals are in these emerging drugs and their combinations, how pure they are or what effect they have on the abusers.

The emerging drugs are purchased and used for their druglike effects. The brand names and product contents (obtained through mixing) have no studies to track potency or side effects and may present serious health effects. It is also difficult to establish potential harm of the emerging drugs due to lack of pharmacology and toxicity information. The contortions of stimulants, depressants, prescription medicine and hard drugs could pose more harm that the commonly abused drugs. It was observed that people abused cocaine at an early age in Nairobi than Mombasa. A number of abusers injected themselves with heroin and cocaine thereby increasing their chances of contracting HIV and Hepatitis C infections (Xian et al., 2008; Chitwood et al., 2003; Nelson et al., 2002).

Shisha also referred to as, goza, hubble-bubble, borry, arhile, narghile, or the 'cocaine of the poor' has spurred concerns among medical experts. Researchers have pointed out that coal or charcoal used in hookah smoking may be hazardous, introducing dangerous substances into the smoke (Akl et al., 2010). The smoke has high levels of carcinogenic benzene, arsenic, lead and nickel, 36 times the tar of a single cigarette (Shihadeh, 2003) and 15 times the carbon monoxide. This is because Carbon Monoxide from coal is 30 times harder to dissolve in water then oxygen. The heated shisha causes chemical reactions in the mixture leading to production of toxic Volatile Organic Compounds (VOCs) such as Acrylamide which leads to nervous system damage; Acrolein causes Irritation to nose, throat and eyes, while Benzene causes Cancer (leukaemia) and Polycyclic Aromatic Hydrocarbons (PAHs) such as Naphthalene which damages the erythrocytes (red blood cells). Some PAHs are highly carcinogenic and can cause lung cancer. According to research carried out by the WHO, one hour of smoking a hookah pipe exposes the user to 100 to 200 times the volume of smoke of a single cigarette (WHO,2005; 2007). This is due to high frequency of puffing, depth of inhalation and length of the smoking session (El-Hakim et al., 1999). The smoke has high levels of carcinogenic benzene, arsenic, lead and nickel, 36 times the tar of a single cigarette and 15 times the carbon monoxide. The heated shisha leads to production of toxic Volatile Organic Compounds (VOCs) and Polycyclic Aromatic Hydrocarbons (PAHs). Some PAHs are highly carcinogenic and can cause lung cancer.

Shisha smokers are at risk of same kind of diseases as those caused by cigarette smoking, which include oral cancer, lung cancer as a results of nicotine and carbon monoxide inhalation; stomach and oesophagus cancers, Chronic Obstructive Pulmonary Disease (COPD) as well as reduced lung function and decreased fertility (Nuwayhid et al., 1998). It was observed that a number of young women in the reproductive age were smoking shisha. Nuwayhid et al. (1998) observed women who smoke one or more water pipes a day during pregnancy give birth to babies with lower birth weights than those born to non smokers and were at an increased risk for respiratory diseases.

Availability, affordability and accessibility of emerging drugs in the outlets were identified during the study. Therefore, by creating departments within the Counties, strengthening NACADA, providing regular follow up ADA trainings and awareness raising activities to all stakeholders especially the youth on the concept of demand reduction, and displaying IEC materials that would serve as promotional material are recommended to decrease availability and usage of drugs in the Counties.

In conclusion, with the problem of the new and emerging drugs being on the increase, the Government must remain vigilant. For this to happen, continued investment on 
legislation, policies, research, trainings, establishment and expansion of treatment and rehabilitation centres, and development of Employee Assistant Programmes (EAPs) is vital. There is urgent need for the Government to be prepared for the emerging drugs and the associated physical and psychological health problems and their drain on health services.

\section{COMPETING INTERESTS}

All authors declare that they have no conflict of interest associated with the publication of this manuscript.

\section{ACKNOWLEDGEMENTS}

We sincerely wish to acknowledge the Government of Kenya through Dr. Wiliam Okedi, the CEO, National Authority Campaign Against Alcohol Drug Abuse (NACADA) for availing the research funds and entrusting us with the project. Special thanks go to Mr. Morris Kamenderi who guided us through the research by providing the necessary infrastructure, discussion, guidance and the platform that made our research possible. We appreciate the Ethical committee of Kenyatta University (KU) and the National Council for Science and Technology (NCST) for research approval, the Research Assistants (RAs) who assisted in

\section{REFERENCES}

Akl, E. A., Gaddam, S, Gunukula, S. K., Honeine, R., Jaoude, P. A., and Irani, J. 2010. The Effects of Water pipe Tobacco Smoking on Health Outcomes: A Systematic Review. International Journal of Epidemiology; 39:834-857

Albert, M. R. and Ostheimer, K. G. 2002. The evolution of current medical and popular attitudes toward ultraviolet light exposure: part 1. Journal of American Academic Dermatology. 47:930-937.

Bivins, R. 2008. Alternative medicine? A history. Oxford University Press,

Browne-Miller, A. 2009. The Praeger International Collection on Addictions: Faces of addiction, then and now. Manchester- UK: ABC-CLIO.

Caliendo, M., and Kopeing, S. 2008. Some Practical Guidance for the Implementation of Propensity Score Matching. Journal of Economic Surveys, Volume 22: 31-72.

Chitwood, D.D, Comerford, M., Sanchez, J.S. 2003. Prevalence and Risk Factors for HIV among Sniffers, Short-Term Injectors, and Long-Term Injectors of Heroin. J Psychoactive Drugs, 35:445453.

Department of Health and Ageing (DoHA) 2011. Drug Information-Other Drugs, National Drugs
All stakeholders, parents, Schools, Colleges, Universities, Government agencies including NACADA, and public health need to be on the lookout for these emerging drugs also referred to as the 'legal high' and find ways of how to deal with a growing list of synthetic, designer and emerging drugs. data collection and connected us to the respondents sometimes under difficult circumstances. The research would not have been possible without the consent from the administration officers in the respective Counties and Districts, all the respondents for their time and cooperation, we sincerely appreciate you. Special appreciation goes to the Key informants and the Focus Group Discussions (FGDs) for providing the backup information that made the research complete. Last but not least we highly appreciate Dr. Ibrahim Macharia for assisting in data analysis and Dr. Nicholas Korir for proof reading.

Campaign, DoHA,
http://www.drugs.health.gov.au.

El-Hakim, I.E. and Uthman, M.A. 1999. Squamous cell carcinoma and keratoacanthoma of lower lip associated with "Goza" and "Shisha" smoking. Int. J. Dermatol. 38(2), 108-110.

European Monitoring Centre for Drugs and Drug Addiction (EMCDDA) 2011. Annual Report 2011: The state of the drug problem in Europe, EMCDDA, Lisbon.

European Monitoring Centre for Drugs and Drug Addiction publishes the 'European Drug Report 2013: Trends and developments' Eurosurveillance, Volume 18, 22, 30 May 2013.

Europol 2011, European Organised Crime Threat Assessment, 2011, Europol, The Hague.

Evans-Brown M., Bellis M. A., and McVeigh J. 2011. Should "legal highs" be regulated as medicinal products? British Medical Journal. 342:1101.

http://www.drugabuse.gov/publications/drugfacts/prescriptio n-over-counter-medications

http://www.thisissouthwales.co.uk/Major-Swanseaconference-legal-highs-new-emerging/story18341403-detail/story

Hu Xingdi, Brian A Primack, Tracey E Barnett, and Robert L Cook. 2011. College students and use of K2: an emerging drug of abuse in young persons. 
Substance Abuse Treatment, Prevention, and Policy 6:16.

NACADA, 2012. Rapid situation assessment of the Status of drug and substance abuse in Kenya, pg 89.

Nelson K.E, Galai N, Safaeian M, Strathdee S.A, Celentano D.D, Vlahov D. 2002. Temporal trends in the incidence of human immunodeficiency virus infection and risk behavior among injection drug users in Baltimore, Maryland, 1988-1998. Am J Epidemiol. 156 :641-653.

Nuwayhid, I, Yamout, B., Ghassan, and Kambria, M. 1998. Narghile (Hubble-Bubble) Smoking, Low Birth Weight and Other Pregnancy Outcomes. American Journal of Epidemiology; 148:375-83.

Shihadeh A. Investigation of mainstream smoke aerosol of the argileh water pipe. Food Chem Toxicol 2003; 41:143- 52.

Stephen, A. Maisto, Mark Galizio, and Gerard J. Connors. 2011. Drug Use and Abuse, Sixth Edition Wadsworth, Cengage Learning.,
WHO 2007. Warns the hookah may pose same risk as cigarettes. USA Today. http://www.usatoday.com/news/health/2007-05-29WHO-hooka N.html.

WHO 2005. Tobacco regulation advisory note: Water pipe tobacco smoking: health effects, research needs, and recommended action by regulators. http://www.who.int/tobacco/global interaction/tobre g/Final.pdf

Xian, X., Jun L., Jianling B., Rongbin Y. 2008: Epidemiology of hepatitis $C$ virus infection among injection drug users in China: Systematic review and metaanalysis. Public Health.122:990-1003.

Young, A. M, Havens J. R., and Leukefeld C.G. 2010. Route of administration for illicit prescription opioids: a comparison of rural and urban drug users. Harm Reduction Journal. 2-7:24 http://www.harmreductionjournal.com/content/7/1/2 $\underline{4}$

\section{APPENDIX I}

List of emerging drugs :

\begin{tabular}{|l|l|}
\hline Shisha- flavored tobacco & Shashaman (Ethiopian, marijuana) \\
\hline Kuber & Zingzing (Solid substance chewed like Kuber) \\
\hline Kukumanga (seed from a marble shaped ' hard drug fruit') & Mkorogo (Heroin, chang'aa and rohypnol) \\
\hline Kachuri (Glue mixed with tobacco) & Rohypnol (prescription medicine) \\
\hline Largactil (prescription medicine) & Laroxyl ( prescription medicine) \\
\hline Artane (prescription medication) & Red devil (prescription medicine) \\
\hline Kamusi (Car petrol) & Dibi (heroin, largactil and rohypnol) \\
\hline $\begin{array}{l}\text { Lego ( pill contains 12\% MDMA and methamphetamine } \\
\text { derivatives) }\end{array}$ & Tambuu (Betel) (areca nut, tobacco and Magadi soda) \\
\hline Jagamaster (Ethanol and jet fuel) & Tap tap (sleeping pill) \\
\hline Jet fuel & Tot (jet fuel, heroin and cocaine) \\
\hline Mau (used the same way as tambuu) & Yee (Boiled formalin and coins) \\
\hline Gotika (drug that resembles Kuber) & Daba (Bhang, rooster and artane) \\
\hline Musi (Paint thinners, glue, petrol and formalin) & Green mamba or black mamba (Spice or K2) \\
\hline Cocktail (heroin, chang'aa and bhang) & Tarnine (shoe polish and tar) \\
\hline Chavis & Matigasi (Changaa and ethanol) \\
\hline Don't touch me (placed on tongue or skin) & Grass ash (Bhang and ash from a certain weed (datura?) \\
\hline $\begin{array}{l}\text { Tangatanga (carbon vapour e.g. in acetone, toluene, } \\
\text { chloroform) }\end{array}$ & $\begin{array}{l}\text { Mshomoro (plant found at the Coast and used like } \\
\text { marijuana) }\end{array}$ \\
\hline Santuri (heroin and valium) & Roy (Rooster, bhang and heroin) \\
\hline Kashata (Glue, ugoro and chang'aa) & Pumbaa (Kukumanga and vinegar) \\
\hline Dongosinyo (Waste products from poppy plant) & Mayee \\
\hline Alto 10 & \\
\hline
\end{tabular}

